\title{
Fluctuating asymmetry in the otoliths as an index of the growth rate of the Japanese anchovy, Engraulis japonicus
}

\author{
SATOSHI WATANABE, MOTOMITSU TAKAHASHI AND YOSHIRO WATANABE \\ Ocean Research Institute, University of Tokyo, Nakano, Tokyo 164-8639, Japan (swatanab@ori.u-tokyo.ac.jp)
}

\begin{abstract}
SUMMARY: Investigations were conducted to test the feasibility of using fluctuating asymmetry (FA) in otoliths as an index of the growth rate and condition of the Japanese anchovy, Engraulis japonicus. The differences between the left and right sides of sagittal otoliths in terms of surface area (SA), perimeter $(P M)$, major axis length (MJ) and minor axis length (MN) were measured in juvenile anchovies shortly after metamorphosis. The absolute values of the side differences were used as the FA index for the 4 traits. Size dependence of the FA traits upon standard length (SL) was eliminated by reducing the SL range centering on the mean value. The distribution patterns of the FA traits were statistically equivalent to those of FA. The FA values for SA and PM had a significant negative correlation to the mean growth rates obtained from the otolith daily ring information. In $M J$ and $M N$, although the correlation was not significant, FA and the mean growth rate seemed to be in a negative relationship, the latter limiting the upper border of the former. FA analyses using otolith traits have been shown to have the potential to determine condition of the Japanese anchovy.
\end{abstract}

\section{KEY WORDS: FA, mean growth rate, sagitta, environmental stress, recruitment success}

\section{INTRODUCTION}

Growth rates in the early stages of development are considered to be one of the most important factors regulating the recruitment success of marine teleost fishes ${ }^{1,2)}$. Investigations of early growth rates have been an important component of the studies on recruitment dynamics of many marine fishes, such as Pacific $^{3)}$ and Japanese sardines ${ }^{4}$, Atlantic $\operatorname{cod}^{5)}$ and the Japanese anchovy ${ }^{6}$. Methods of growth rate estimation employ calculations based on age determination of the specimens, which are intricate and time-consuming. Age determination may be impossible or difficult to perform on some species without a distinctive age character or on those that cannot be reared to confirm the formation periodicity of an age character.

Developmental instability measured as fluctuating asymmetry (FA) has been used as an indicator of condition or fitness in a variety of organisms. FA is a small random departure from perfect bilateral symmetry, resulting from the inability of individuals to undergo identical development of a bilateral trait on both sides of the body ${ }^{7}$. Developmental instability is supposed to be caused by a reduction in the capability to maintain homeostasis to withstand environmental disturbances encountered during development ${ }^{8)}$; therefore, it can be used as a measure of environmental stress. Attempts have been made in some fishes to examine the possibility of using FA to assess environmental stress caused by pollutants $^{9,10)}$, the $\mathrm{pH}$ level ${ }^{11)}$ and parasitism ${ }^{12)}$, the results of which showed either a presence or absence of correlation between stress and FA depending upon the species, traits and stress factors examined, indicating the necessity of case-specific investigations. FA in the otoliths of the European anchovy (Engraulis encrasicolus) has been found to negatively correlate to the condition (i.e. body size and recent otolith growth) of the larvae ${ }^{13)}$, suggesting that FA of the otoliths can be used as an indicator of the condition in larval European anchovies.

If FA of a certain trait is found to be correlated to the growth rate, by using that correlation one should be able to roughly estimate and compare the growth rates, as well as the condition, among different samples of a fish species without determining age. In the present study, the feasibility to use otolith FA parameters as an index of the growth rate in the Japanese anchovy, Engraulis japonicus, was tested. Correlations between growth rates and various otolith FA parameters were examined.

\section{MATERIALS AND METHODS}

\section{Sample collection}

The Japanese anchovies, Engraulis japonicus, in their early juvenile stage were collected by subsurface trawls in the Kuroshio-Oyashio transition region aboard the R/V Tanshu-Maru of the National Research Institute of Fisheries Science, from May 27 
to June 26 in 1997, from May 14 to June 14 in 1998 and from May 24 to June 15 in 1999. The net had an opening of $25 \times 25 \mathrm{~m}$ and a cod end with a $1.0 \mathrm{~cm}$ in mesh aperture, and was towed three times a night at 3 to 4 knots with the bottom of the opening at depths shallower than $25 \mathrm{~m}$. Juveniles shortly after metamorphosis distinguished by the exclusive presence of guanine in the peritoneum were subsampled from the catches and stored at $-25^{\circ} \mathrm{C}$ for examination.

\section{Growth rate determination}

The standard lengths (SL) of the juveniles were measured to the nearest $0.1 \mathrm{~mm}$ with a digital caliper. Sagittal otoliths were dissected out, cleaned under a dissecting microscope, and mounted on a glass slide with enamel resin. Otoliths from juveniles larger than approximately $35 \mathrm{~mm} \mathrm{SL}$ were ground with 2000 -grit sandpaper and smoothed with 10000-grit lapping film. The number of prepared otoliths was 288 pairs.

Otolith growth rings are deposited on a daily basis in the Japanese anchovy ${ }^{14}$. The total number of daily growth rings in an otolith was counted using an otolith measurement system (RATOC System Engineering Inc.) consisting of a light microscope, a color $\mathrm{CCD}$ camera, a video monitor, and an image analyzer controlled by a computer. The mean juvenile growth rate (G) was calculated as: $G=\left(L_{c}-2.7\right) / d$, where $L_{c}=\mathrm{SL}$ of juveniles at catch; $2.7=\mathrm{SL}$ of newly hatched larva ${ }^{14)} ; d=$ age in days.

\section{Developmental instability analysis}

Developmental instability of the anchovy otoliths was measured as fluctuating asymmetry (FA). Microscopic otolith images were captured by the CCD camera. The images were constantly focused on the outer margins of the otoliths to minimize measuring error. Analyses of the otolith images were done using an image analyzing software (Scion Image Beta 3b, Scion Corporation). The otolith surface area (SA, i.e. the sagittal projective area), the perimeter (PM), and major axis length (MJ) and minor axis length (MN) of the best-fitting ellipsoids were measured.

In order to examine the dependence of the values of each otolith trait upon SL, regression analyses were performed between $\operatorname{Ln}|\mathrm{L}-\mathrm{R}|$ and $\operatorname{LnSL}$, as recommended by Palmer and Strobeck ${ }^{16)}$, where $L$ and $R$ are the values of the left and right otoliths, respectively. Palmer ${ }^{(7)}$ recommended avoiding the elimination of size dependence of FA among samples because it could partially or completely obscure the associations between FA and condition ${ }^{16)}$. Based on the results of the regression analyses, the SL range of each trait was narrowed down centering on the mean value to such a level that no longer showed significant $(\alpha=0.05)$ size dependence, and asymmetry was calculated as: $F A=|L-R|$.

FA is defined statistically in terms of the L-R distributions being in a normal or leptokurtic distribution centering on the mean of zero ${ }^{5,(6,18)}$. In order to test this prerequisite, the normality of the L-R distribution of each asymmetry trait was tested by a chi-squire test for goodness of fit (10 divisions, d.f. $=7$ ), and the kurtosis was tested against zero by a one-sample $t$-test ${ }^{(9)}$. The differences between the left and right values of each trait were tested by a two-way ANOVA to examine the directionality (skewness) in the asymmetry ${ }^{20)}$.

\section{RESULTS}

\section{Fish size, age and growth rate}

Of the 288 pairs of otoliths prepared, 4 pairs were excluded from analyses due to apparent deformation, which was characterized by vaterite morph crystallization of calcium carbonate ${ }^{21)}$, resulting in abnormal transparency and irregular morphology.

Although the juvenile anchovy were in the same developmental stage, they had relatively wide ranges of body size and age. The body size ranged from 26.4 to $47.0 \mathrm{~mm} \mathrm{SL}$ with a mean of $35.0 \pm 3.6 \mathrm{~mm}(+\mathrm{SD})$. The age ranged from 34 to $88 \mathrm{~d}$, and the growth rates also had a wide range from 0.42 to $0.91 \mathrm{~mm} / \mathrm{d}$.

Table 1. Size-dependence of FA values of the otolith traits in Engraulis japonicus.

\begin{tabular}{cccccc}
\hline SL range & Ln SA & Ln PM & Ln MJ & Ln MN & n \\
\hline \hline $29-41$ & ns & ns & ns & ns & 258 \\
$28-42$ & ns & ns & ns & 0.025 & 269 \\
$27-43$ & ns & ns & ns & 0.011 & 276 \\
$26-44$ & ns & ns & ns & 0.007 & 281 \\
$25-45$ & 0.035 & ns & ns & 0.004 & 282 \\
$24-46$ & 0.044 & ns & ns & 0.004 & 283 \\
all & 0.020 & ns & ns & 0.003 & 284 \\
\hline
\end{tabular}

Numbers are $\mathrm{p}$ values for the correlation between LnSL and LnFA. $\mathrm{SL}=$ standard length, $\mathrm{SA}=$ surface area, $\mathrm{PM}=$ =perimeter, $\mathrm{MJ}=$ major axis, $\mathrm{MN}=$ minor axis of otolith. (ns: $\mathrm{p}>0.05$ ) See text for full description.

\section{Size-dependence of otolith asymmetry traits}

The degree of dependence of FA values upon body size varied among the 4 traits (Table 1$)$. PM $\left(r^{2}=0.002\right.$, 
$\mathrm{p}=0.49)$ and $\mathrm{MJ} \quad\left(\mathrm{r}^{2}=0.004, \mathrm{p}=0.28\right)$ were not significantly size-dependent; therefore, all 284 pairs were used for further analyses. SA showed significant size-dependence upon SL $\left(r^{2}=0.02 p=0.02\right)$, and the $\mathrm{SL}$ range was narrowed down to $26-44 \mathrm{~mm}$ centering on the mean value of $35.0 \mathrm{~mm}(p>0.06, n=281)$. MN was the most size-dependent $\left(r^{2}=0.03, p=0.003\right)$ among the 4 traits; the SL range used for $\mathrm{MN}$ was $29-41 \mathrm{~mm}(\mathrm{p}>0.07, \mathrm{n}=258)$.

\section{Normality of asymmetry traits}

Normality tests of FA distributions of otolith traits showed contradictory results (Table 2). While normality of SA distribution was rejected by a chi-squire test for goodness of fit $(p<0.001)$, the distributions of $\mathrm{PM}, \mathrm{MJ}$ and $\mathrm{MN}$ were not statistically different from normal $(p>0.1, p>0.1, p>0.05$, respectively). Distributions of all four traits were significantly leptokurtic $(p<0.01)$ as shown by a one-sample t-test, denying the normality of the distributions. Tests for skewness of the distributions by a two-way ANOVA showed that L-R differences of the four traits were not significant: $S A(p=0.76), P M$ $(\mathrm{p}=0.82), \mathrm{MJ}(\mathrm{p}=0.97)$ and $\mathrm{MN}(\mathrm{p}=0.57)$, indicating the absence of directionality in the distributions.

Table 2. Tests of distribution pattern of otolith FA traits in Engraulis japonicus.

\begin{tabular}{ccccc}
\hline & normality & kurtosis & skewness & n \\
\hline \hline SA & $\mathrm{p}<0.01$ & $1.32(\mathrm{p}<0.01)$ & $\mathrm{p}=0.757$ & 281 \\
PM & $\mathrm{p}>0.1$ & $1.42(\mathrm{p}<0.02)$ & $\mathrm{p}=0.824$ & 284 \\
$\mathrm{MJ}$ & $\mathrm{p}>0.1$ & $0.97(\mathrm{p}<0.03)$ & $\mathrm{p}=0.974$ & 284 \\
MN & $\mathrm{p}>0.05$ & $0.98(\mathrm{p}<0.04)$ & $\mathrm{p}=0.571$ & 258 \\
\hline
\end{tabular}

Chi-square tests for goodness of fit $(\mathrm{d} . \mathrm{f},=7)$ rejected the normality of SA distribution. All four distributions were significantly leptokurtic (one-sample t-test). Skewness was not significant in the four distributions (two-way ANOVA on L-R differences). $\mathrm{SA}=$ surface area, $\mathrm{PM=perimeter,} \mathrm{MJ}=$ major axis, $\mathrm{MN}=$ minor axis.

\section{FA as a function of mean growth rate}

Significant negative correlations were detected between the mean growth rates $(G)$ and the FA values of SA (Fig. 1, $\left.\mathrm{r}^{2}=0.14, \mathrm{p}<0.05\right)$ and PM $\left(\mathrm{r}^{2}=0.14\right.$, $p<0.05$ ). The FA values of $M J$ and $M N$ were not significantly correlated to $G(p>0.23$ and $p>0.50$, respectively). In the plots of $G$ against otolith $F A$ values (Fig. 1), the range of the FA values at a certain $G$ seemed to decrease with the increase in $G$ value, making the distribution patterns triangular. The upper border of FA values seemed to be limited by the mean growth rates.

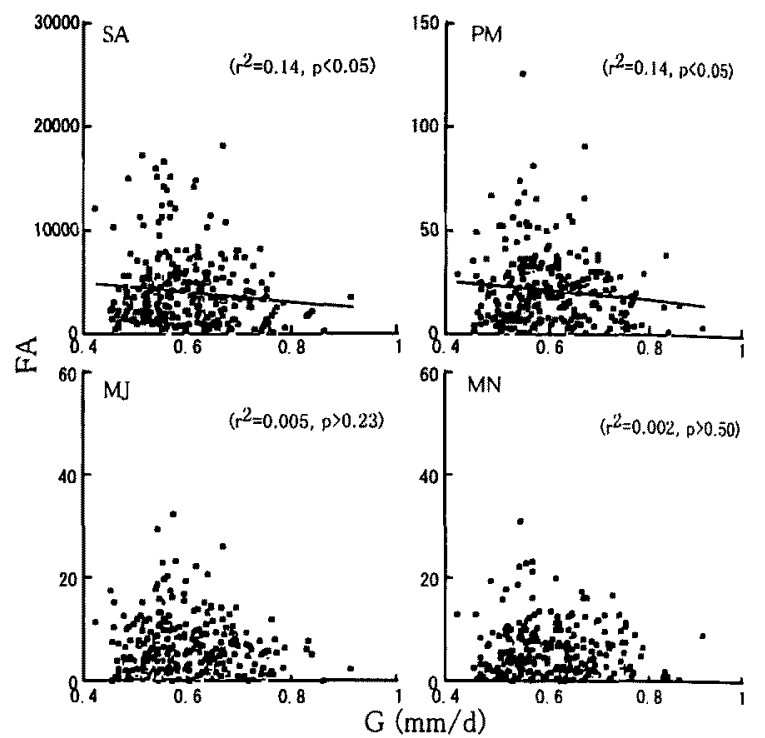

Fig. 1. Relationship between otolith $F A$ values and mean growth rate of juvenile Engraulis japonicus. Correlations were significantly negative in $\mathrm{SA}$ and PM. G-mean growth rate, $\mathrm{SA}=$ surface area, $\mathrm{M}=$ perimeter, $\mathrm{MJ}=$ =major axis, $\mathrm{MN}=$ minor axis.

\section{DISCUSSION}

Although the juvenile anchovies were in the same developmental stage shortly after metamorphosis, large variations were observed in the standard length, age and mean growth rate. Since the juveniles in a certain short period of development were observed, these variations are considered to be produced by individual variations rather than by the duration of the developmental stage. It was predicted that the juveniles with large variations would quickly perish, converging to individuals with certain characteristics. As one of such characteristics, the mean growth rate was focused on, and it was found to be related to fluctuating asymmetry in the sagittal otoliths in the present study.

It was confirmed that the frequency distribution patterns of the four otolith traits were not significantly different from FA, and thus they can be used for FA analyses. However, the three tests conducted to examine the distribution patterns showed slightly contradictory results. Chi-square tests for goodness of fit rejected the normality of SA but not that of the other three traits. Although the results of skewness tests by a two-way ANOVA did not contradict these results, kurtosis was shown to be significantly positive (i.e. leptokurtic) by a one-sample t-test for the four otolith traits, indicating that they are not normally distributed. FA traits used to be considered to have a normal distribution ${ }^{6)}$; however, recent 
studies imply that the distributions may also be leptokurtic $^{(8)}$. Although the mathematical reasons for the statistical contradictions observed in the present study were not understood, it is recommended that a combination of one-sample t-test for kurtosis and two-way ANOVA for skewness be used for preliminary examination of FA analyses.

Unlike meristic characters, the otolith FA traits, being of a morphometric character, were significantly size-dependent. In the present study, the size effects were not corrected, and they were eliminated to statistically non-significant levels by reducing the standard length range as recommended by Palmer ${ }^{16)}$. However, size effects apparently exist, possibly obscuring the relationship between mean growth rates and FA. Low, yet significant, values of the coefficient of correlation between mean growth rate and FA may partially result from the usage of a size-biased FA index. An appropriate method of size-effect corrections for FA traits should be developed to improve the sensitivity and accuracy of the FA method.

Slow growth rates are thought to reduce the probability of recruitment success of fishes ${ }^{1,2)}$. This growth-mortality hypothesis was supported by the present study. Mean growth rates were found to be negatively correlated to the otolith FA in the Japanese anchovy. Since higher FA values are a sign of fishes being in a stressful environment that deteriorates their condition $^{8,13)}$, juvenile anchovies with slower growth rates are considered to be in poorer conditions, and their probability of mortality is expected to be higher. The present study has shown that FA analyses using otolith traits have the potential to determine the conditions of stressful environments or possible causes of early mortality. FA analyses of individuals reared under various conditions should be carried out for further understanding of recruitment mechanisms in Japanese anchovies.

\section{ACKNOWLEDGMENTS}

This study was supported in part by Grants-in-Aid for Science Research from the Ministry of Education, Japan.

\section{REFERENCES}

1. Houde ED. Fish early life dynamics and recruitment variability. Am. Fish. Soc. Symp. 1987; 2: 17-29.

2. Houde ED. Subtleties and episodes in the early life of fishes. J. Fish Biol. 1989; 35 (suppl.): 29-38.

3. Butler, JL. Mortality and recruitment of Pacific sardine, Sardinops sagax caerulea, larvae in the California Current. Can. J. Fish. Aquat. Sci. 1991; 48: 1713-1723.
4. Watanabe Y, Zenitani H, Kimura R. Population decline of the Japanese sardine, Sardinops melanostictus, owing to recruitment failures. Can. J. Fish. Aquat. Sci. 1995; 53: 55-61.

5. Meekan MG, Fortier L. Selection for fast growth during the larval life of Atlantic cod Gadus morhua on the Scotian Shelf. Mar. Ecol. Prog. Ser. 1996; 137: 25-37.

6. Takahashi M, Watanabe Y, Kinoshita T, Watanabe C. Growth of larval and early juvenile Japanese anchovy, Engraulis japonicus, in the Kuroshio-Oyashio transition region. Fish. Oceanogr. 2001; 10: 235-247.

7. Van Valen L. A study of fluctuating asymmetry. Evolution $1962 ; 16: 125-142$.

8. Somarakis S, Kostikas I, Tsimenides N. Fluctuating asymmetry in the otoliths of larval fish as an indicator of condition: conceptual and methodological aspects. J. Fish. Biol. (suppl. A) 1997; 51: 30-38.

9. Allenbach DM, Sullivan KB, Lydy MJ. Higher fluctuating asymmetry as a measure of susceptibility to pesticides in fishes. Env. Tox. Chem. 1998; 18: 899-905.

10. Vollestad LA, Fjeld E, Haugen $T$, Øxnevad SA. Developmental instability in grayling (Thymallus thymallus) exposed to methylmercury during embryogenesis. Env. Pollut. 1998; 101: 349-354.

11. Østbye K, Øxnevad SA, Vøllestad A. Developmental stability in perch (Perca fluviatilis) in acidic aluminium-rich lakes. Can. J. Zool. 1997; 75: 919-928.

12. Berg OK, Adkison MD, Quinn TP. Bilateral asymmetry, sexual dimorphism, and nematode parasites in mature male sockeye salmon Oncorhynchus nerka. Northwest Sci. 1997; 71: 305-312.

13. Somarakis S, Kostikas I, Peristeraki N, Tsimenides N. Fluctuating asymmetry in the otoliths of larval anchovy Engraulis encrasicolus and the use of developmental instability as an indicator of condition in larval fish. Mar. Ecol. Prog. Ser. 1997; 151: 191-203.

14. Tsuji S, Aoyama T. Daily growth increments in otoliths of Japanese anchovy larvae, Engraulis japonica. Bull. Japan. Soc. Sci. Fish. 1984; 50; 1105-1108.

15. Fukuhara O. Development and growth of laboratory reared, Engraulis japonicus (Houttuyn), larvae. J. Fish Biol. 1983; 23: 641-652.

16. Palmer AR, Strobeck C. Fluctuating asymmetry: measurement, analysis. patterns. Ann. Rev. Ecol. Syst. 1986; 17: 391-421.

17. Palmer AR. Fluctuating asymmetry analyses: a primer. In Markow TA (ed) Developmental instability: its origins and evolutionary implications. Kluwer, Dordrecht, Netherlands, 1984, pp. 335-364.

18. Leung B, Forbes MR. Modeling fluctuating asymmetry in relation to stress and fitness. OIKOS 1997; 78: 397-405.

19. Sokal RR, Rohlf FJ. Biometry 2nd edition W. H. Freeman and Co New York, 1981.

20. Pomory $\mathrm{CM}$. Fluctuating asymmetry: biological relevance or statistical noise? Anim. Behav. 1997; 53: 225-227.

21. Gauldie RW. Polymorphic crystalline structure of fish otoliths. J. Morph. 1993; 218: 1-28. 